specialized document searches required in the operation and maintenance of sophisticated equipment. The objective was to break down the intimidating barriers often found in libraries in the Middle East.

It was not long before students realized that identifying an information need and articulating that need led to a positive resolution-whether it was the correct usage of a word or a complicated schematic.

This introduction to basic reference publications, combined with a working knowledge of the card catalog, made it possible in time for the student to identify an information need, search the card catalog, identify a source, and locate information required independent of librarian assistance. Our objective had been reached.

Many practices of the Naval Forces School Li- brary at Jubail were unconventional by U.S. standards. It was, however, a unique environment with particular requirements. Regretfully our contract had concluded while on the threshold of the next and final phase of academic library development. The library was about to go to an online system with the ability to interface with other RSNF libraries. A new academic building had been completed, ten thousand volumes had been identified and ordered, and the curricula began to indicate a move from equipment-oriented training to a more traditional college engineering program.

Editor's Note: The author is currently working with Telemedia in Cairo to consult on the development of a library for the Egyptian Air Force Academy to support a bachelor of science degree in aeronautical engineering and computer science.

\title{
Deacidification dialogue
}

\author{
By Peter G. Sparks \\ Director for Preservation \\ Library of Congress
}

and Richard D. Smith

President, Wei T'o Associates

Matteson, Illinois

\section{Further discussion on mass deacidification processes stimulated by Richard Smith's article in the December}

CむRL News.

Editor's Note: Peter Sparks at the Library of Congress was asked to comment on "Mass deacidification: The Wei T'o way" in the December issue, $p p$. 588-593. Following his remarks are comments by author Richard Smith.

$\mathbf{T}$ hank you for the opportunity to comment on the article by Richard Smith of Wei T'o Associates. A short response is not adequate for extensive dis- cussion of the technical claims in Richard Smith's article. However, the position of the Library of Congress Preservation Office on several issues and its own process needs to be stated.

Dr. Smith appears to view other mass deacidification processes to be competitive with his own. The Library of Congress Preservation Office does not share that view. We believe that the processes presently available or under development present reasonable alternatives, from which an institution 
may select a process that best suits its individual needs and requirements. For example, the Library of Congress, with its extensive and varied book and non-book collections, places considerable emphasis on cost effectiveness and efficiency. Hence its selection of the diethyl zinc (DEZ) gaseous process, which permits high quality, efficient deacidification of very large numbers of any type of collection material, without a costly, labor-intensive preselection step. A manual, item-by-item preselection procedure is employed in known liquid phase processes to avoid color and ink transfer problems.

Costs of facility construction are notoriously difficult to compare. All too often cost estimates are prepared without adequate documentation on the amount of engineering and equipment. The Library of Congress facility costs are based on indepth engineering studies and actual cost quotes from equipment suppliers. The $\$ 11.5$ million pays for a facility that is designed to treat one million books per year, 24 hours a day, 7 days a week, and that will last 30 years. In addition, the facility will have quality control and development laboratories and be expandable for higher output in the future at a reasonable cost. I would caution prospective buyers of any deacidification process to look very carefully at construction costs before coming to hard conclusions about comparative facility costs.

Our own experience at LC is instructive. With a modest amount of engineering input we thought we were going to be able to build a facility for between $\$ 2.5$ and $\$ 3$ million. However, when all the estimates were in and all considerations taken into account costs increased.

No deacidification process has a monopoly on the introduction of modifications to extend its usefulness. Introduction of steps to reduce oxidative, photochemical and biological deterioration, and to strengthen paper, are reasonable goals. However, considerable research, testing and evaluation are required to transform these ideas into a demonstrated, cost effective and safe mass process.

The gas phase diethyl zinc process developed by the Library of Congress Preservation Research and Testing Office has been most thoroughly investigated. We have accumulated a substantial amount of scientific data which prove that this process uniformly and consistently neutralizes all excess acid in the paper, leaves a uniformly distributed alkaline reserve in all regions of the book page and the paper fiber, increases the life expectancy of all types of paper by a factor of four to five times their original life at time of treatment, has no noticeable chemical reactions or side effects on the book and design materials, has no significant toxicological risk to human beings, and has the added benefit of being a good fungistat which retards the growth of mold in paper.

Moreover, and very importantly, this process has actually been demonstrated to deacidify thousands of books at the same time. It has been engineered to a scale that will enable the Library of
Congress to complete the preservation of the majority of its retrospective book collections in 20 years while treating all new incoming material. The Library of Congress research laboratory may undertake further development of its DEZ process to strengthen paper, add antioxidants, etc. However, until such time that this research has advanced so far as to demonstrate conclusively that such enhancements are possible, we will not make any claims in this area. We will continue our program to research carefully all preservation treatment processes that we plan to use on our own collections and to present the results of our studies at conferences and in publications.-Peter G. Sparks.

\section{Dr. Smith replies:}

Thank you for the privilege of responding to the thoughtful remarks from Dr. Sparks regarding the LC diethyl zinc deacidification system. I have nothing but admiration for the engineering skills and dedication of the scientists responsible for inventing and developing the LC deacidification system and the leadership of Dr. Sparks in bringing it to reality.

With reference to questions implied by Dr. Sparks's wording, "technical claims," my report about results with the Wei T'o System at the Public Archives of Canada can be substantiated. With reference to competition, I certainly agree that the processes currently available or under development present practical alternatives, but believe the very fact that these alternatives exist is evidence that competition exists.

Some confusion apparently exists in Dr. Sparks's mind regarding the nature of the Wei T"o "liquified gas” Nonaqueous Book Deacidification System. It does not include an expensive, labor-intensive, preselection process. The treatment costs (excluding capital costs) of both systems appear to be equivalent. Consequently, the reasonable conclusion is either both the LC and the Wei T'o processes are outrageously expensive or both are extraordinarily efficient.

I strongly agree that the cost of facility construction is difficult to predict or compare. This fact points out the great advantages of the Wei T'o System: 1) only 2,000 square feet of floor space are needed in an existing library building; 2) the system is built with fixed cost components obtainable on the open market; 3) the known costs are based on four years of operating experience. These advantages can be compared with the high cost and unproven nature of the LC mass deacidifcation facility.

Although I am in full agreement that all deacidification systems can be modified to extend their usefulness, the fact remains that the Wei T'o System is the only system where deacidification was planned as one element of an all round, integrated preservation system.

The Wei T'o deacidification process is the result of 20 years work including seven years at the Uni- 
versity of Chicago and the Institute of Paper Chemistry. The process has been thoroughly investigated. I am in complete agreement with Dr. Sparks's list of admirable qualities for the LC System, but respectfully suggest that an equally admirable list exists for the Wei T'o System.

Dr. Sparks's suggestion that the LC System has "no significant toxicological risks to human beings" can be accepted only if one believes machinery built by man is $100 \%$ safe. Otherwise, the pyrophoric properties of diethyl zinc remain a major problem.

Dr. Sparks's sentence, "Moreover, and very importantly, this process has actually been demonstrated to deacidify thousands of books at the same time," confuses me. I am unable to reconcile it with an LC scientist's report that $40 \%$ of the books in the LC 5,000-book test were incompletely or not at all deacidified. ${ }^{1}$ The white powder deposits defacing

${ }^{1}$ Donald Sebera, "The Technology and Chemistry of Deacidification with Diethyl Zinc," Book many of the deacidified books were identified as the "Tiffany Effect." These problems are said to have been resolved for the final design based on data from a series of eighteen 100-book tests.

I would like to repeat that I am impressed by the scope of the LC plan. The new facility will not only deacidify all incoming material each year, but also complete the preservation of most of LC's retrospective book collections during the next twenty years. This is a truly significant undertaking and it reflects great credit on Dr. Sparks and the Library of Congress.

In summary, the question which each college and research library must now decide is which of these two excellent, alternative deacidification systems best suits its needs. - Richard D. Smith.

and Paper Group, American Institute for Conservation Annual Meeting, May 28, 1983, Baltimore, Md. Tape available from Cassette Recording Company, 1377 E. Stroop Rd., Box 20453, Dayton, OH 45429; (513) 293-2607.

\section{Library scholars in residence at the University of Washington}

Since 1980 the University of Washington Libraries, Seattle, have been host to a succession of scholars from East Asia studying library automation with the general assistance of Karl Lo, head of the East Asia Library, and other librarians in the system.

The first proposal to send staff to Washington to study automation came from the Chinese Academy of Sciences in Beijing after Karl Lo had given a presentation on the subject there. In 1980 Wang Xiaoning became the first librarian to be sent to the United States by the People's Republic of China. After slightly less than two years at the university, Wang won a scholarship to the University of $\mathrm{Al}$ berta where she is now pursuing a doctorate in computer science.

The second scholar in residence was Susumu Ushizaki from the Rikkyo University Library in Tokyo. His study tour had been initiated during an acquisition trip to Tokyo by Teruko Chin, Japan librarian in the East Asia Library. Ushizaki spent a year in the library studying automation.

The third and current scholar in residence is Wang Yen, sent by the library of the Chinese Academy of Sciences in Chengdu in 1983.

With each of the librarians from East Asia, Karl Lo has provided information and has also been advisor to classes on automation available elsewhere in the university. The visiting scholars have been pleased with UW's encouragement and support. Washington in turn has welcomed the chance to host librarians which may result in better bibliographic control and management in other libraries and which promotes the international sharing of resources and experience.-Lynne Rhoads, Library Publications Officer, University of Washington.

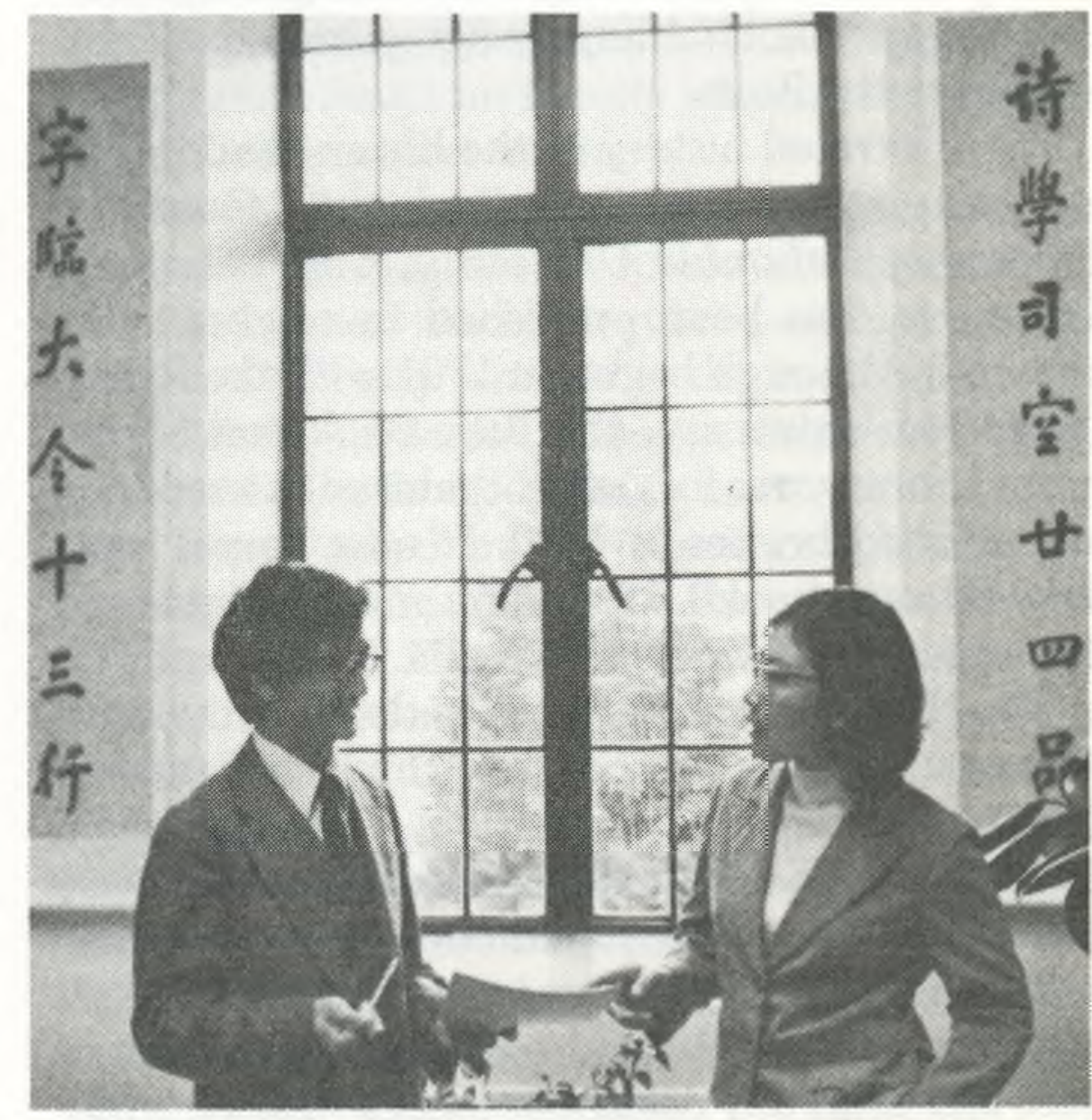

Karl Lo (left) with Wang Xiaoning, the first PRC librarian to be sent to the United States. 